\title{
Some new fixed point theorems for $\alpha$-Geraghty contraction type maps in metric spaces
}

\section{Ovidiu Popescu}

\section{"Correspondence:}

ovidiu.popescu@unitbv.ro

Department of Mathematics and

Computer Sciences, Transilvania

University, Iuliu Maniu 50, Braşov,

505801, Romania

\begin{abstract}
We generalize the results obtained in Cho et al. (Fixed Point Theory Appl. 2013:329,

2013) and give other conditions to prove the existence and uniqueness of a fixed point of $\alpha$-Geraghty contraction type maps in the context of a complete metric space.
\end{abstract}

\section{Introduction and preliminaries}

The Banach contraction principle [1] is one of the earliest and most important results in fixed point theory. Because of its application in many disciplines such as chemistry, physics, biology, computer science and many branches of mathematics, a lot of authors have improved, generalized and extended this classical result in nonlinear analysis; see, e.g., $[2-10]$ and the references therein.

One of the interesting results was given by Geraghty [6] in the setting of complete metric spaces by considering an auxiliary function. Later, Amini-Harandi and Emami [3] characterized the result of Geraghty in the context of a partially ordered complete metric space, and Caballero et al. [11] discussed the existence of a best proximity point of Geraghty contraction. Gordji et al. [12] defined the notion of $\psi$-Geraghty type contraction and supposedly improved and extended the results of Amini-Harandi and Emami [3]. Recently, Cho, Bae and Karapinar [13] defined the concept of $\alpha$-Geraghty contraction type maps in the setting of a metric space and proved the existence and uniqueness of a fixed point of such maps in the context of a complete metric space. Very recently, Karapınar and Samet [14] proved that the results of Gordji et al. [12] and all results inspired by the paper of Gordji et al. [12] are equivalent to existing results in the literature. For other results related to Geraghty contractions, see [13-23].

In this paper, we generalize the results obtained in [13] and give other conditions to prove the existence and uniqueness of a fixed point of $\alpha$-Geraghty contraction type maps in the context of a complete metric space. Now, we remind some basic definitions and remarkable results on the topic in the literature.

Definition 1 [24] Let $T: X \rightarrow X$ be a map and $\alpha: X \times X \rightarrow R$ be a function. Then $T$ is said to be $\alpha$-admissible if $\alpha(x, y) \geq 1$ implies $\alpha(T x, T y) \geq 1$.

Definition 2 [16] A map $T: X \rightarrow X$ is said to be triangular $\alpha$-admissible if:

@2014 Popescu; licensee Springer. This is an Open Access article distributed under the terms of the Creative Commons Attribution License (http://creativecommons.org/licenses/by/2.0), which permits unrestricted use, distribution, and reproduction in any medium, provided the original work is properly cited. 
(T1) $T$ is $\alpha$-admissible,

(T2) $\alpha(x, z) \geq 1$ and $\alpha(z, y) \geq 1$ imply $\alpha(x, y) \geq 1$.

Let $\mathcal{F}$ be the family of all functions $\beta:[0, \infty) \rightarrow[0,1)$ which satisfies the condition

$$
\lim _{n \rightarrow \infty} \beta\left(t_{n}\right)=1 \text { implies } \lim _{n \rightarrow \infty} t_{n}=0 .
$$

By using such maps, Geraghty [6] proved the following result.

Theorem 1 Let $(X, d)$ be a complete metric space and let $T$ be a mapping on $X$. Suppose that there exists $\beta \in \mathcal{F}$ such that for all $x, y \in X$,

$$
d(T x, T y) \leq \beta(d(x, y)) d(x, y) .
$$

Then $T$ has a unique fixed point $x_{*} \in X$ and $\left\{T^{n} x\right\}$ converges to $x_{*}$ for each $x \in X$.

Amini-Harandi and Emami [3] reconsidered Theorem 1 in the framework of partially ordered metric spaces.

Theorem 2 Let $(X, \preceq, d)$ be a partially ordered complete metric space. Let $f: X \rightarrow X$ be an increasing mapping such that there exists an element $x_{0} \in X$ with $x_{0} \preceq f x_{0}$. If there exists $\alpha \in \mathcal{F}$ such that

$$
d(f x, f y) \leq \alpha(d(x, y)) d(x, y)
$$

for each $x, y \in X$ with $x \geq y$, then $f$ has a fixed point provided that either $f$ is continuous or $X$ is such that if an increasing sequence $\left\{x_{n}\right\} \rightarrow x$, then $x_{n} \preceq x$ for all $n$. Besides, if for each $x, y \in X$ there exists $z \in X$ which is comparable to $x$ and $y$, then $f$ has a unique fixed point.

Definition 3 [24] Let $(X, d)$ be a metric space and $\alpha: X \times X \rightarrow R$ be a function. A map $T: X \rightarrow X$ is called a generalized $\alpha$-Geraghty contraction type map if there exists $\beta \in \mathcal{F}$ such that for all $x, y \in X$,

$$
\alpha(x, y) d(T x, T y) \leq \beta(M(x, y)) M(x, y)
$$

where $M(x, y)=\max \{d(x, y), d(x, T x), d(y, T y)\}$.

Cho et al. [13] proved the following interesting result.

Theorem 3 Let $(X, d)$ be a complete metric space, $\alpha: X \times X \rightarrow R$ be a function, and let $T: X \rightarrow X$ be a map. Suppose that the following conditions are satisfied:

(1) $T$ is a generalized $\alpha$-Geraghty contraction type map;

(2) $T$ is triangular $\alpha$-admissible;

(3) there exists $x_{1} \in X$ such that $\alpha\left(x_{1}, T x_{1}\right) \geq 1$;

(4) $T$ is continuous.

Then $T$ has a fixed point $x_{*} \in X$ and $\left\{T^{n} x_{1}\right\}$ converges to $x_{*}$. 
The continuity of the mapping $T$ can be replaced by a suitable condition $\left(4^{\prime}\right)$ (see Theorem $2.2[13])$ :

(4') If $\left\{x_{n}\right\}$ is a sequence in $X$ such that $\alpha\left(x_{n}, x_{n+1}\right) \geq 1$ for all $n$ and $x_{n} \rightarrow x \in X$ as $n \rightarrow \infty$, then there exists a subsequence $\left\{x_{n(k)}\right\}$ of $\left\{x_{n}\right\}$ such that $\alpha\left(x_{n(k)}, x\right) \geq 1$ for all $k$.

Adding the condition $(\mathrm{H})$,

(H) For all $x, y \in \operatorname{Fix}(T)$, there exists $z \in X$ such that $\alpha(x, z) \geq 1$ and $\alpha(z, y) \geq 1$, where $\operatorname{Fix}(T)$ denotes the set of fixed points of $T$,

to the hypotheses of Theorem 3, Cho et al. [13] obtained that $x_{*}$ is the unique fixed point of $T$ (see Theorem 2.3 [13]). However, we think that this condition is not appropriate. To verify such a condition assumes to know $\operatorname{Fix}(T)$ and then the uniqueness of a fixed point is trivial. Also, we think that the following condition is not more appropriate:

(iii) [16] For all $x \neq y \in X$, there exists $v \in X$ such that $\alpha(x, v) \geq 1$ and $\alpha(v, y) \geq 1$. This condition implies $\alpha(x, y) \geq 1$ for all $x \neq y \in X$, and then the utility of $\alpha$ is 0 . For more details, see Theorem 19 [16].

\section{Fixed point theorems}

In this section, we prove that the results of Cho et al. [13] are still available if we replace condition (2) of Theorem 3 with a weaker condition, and if we extend the notion of generalized $\alpha$-Geraghty contraction type map.

Definition 4 Let $(X, d)$ be a complete metric space and let $\alpha: X \times X \rightarrow R$ be a function. A map $T: X \rightarrow X$ is called a generalized $\alpha$-Geraghty contraction type map if there exists $\beta \in \mathcal{F}$ such that for all $x, y \in X$,

$$
\alpha(x, y) d(T x, T y) \leq \beta\left(M_{T}(x, y)\right) M_{T}(x, y),
$$

where $M_{T}(x, y)=\max \{d(x, y), d(x, T x), d(y, T y),[d(x, T y)+d(y, T x)] / 2\}$.

Now, we introduce two new concepts.

Definition 5 Let $T: X \rightarrow X$ be a map and $\alpha: X \times X \rightarrow R$ be a function. Then $T$ is said to be $\alpha$-orbital admissible if

(T3) $\alpha(x, T x) \geq 1$ implies $\alpha\left(T x, T^{2} x\right) \geq 1$.

Definition 6 Let $T: X \rightarrow X$ be a map and $\alpha: X \times X \rightarrow R$ be a function. Then $T$ is said to be triangular $\alpha$-orbital admissible if $T$ is $\alpha$-orbital admissible and

(T4) $\alpha(x, y) \geq 1$ and $\alpha(y, T y) \geq 1$ imply $\alpha(x, T y) \geq 1$.

Obviously, every $\alpha$-admissible mapping is an $\alpha$-orbital admissible mapping and every triangular $\alpha$-admissible mapping is a triangular $\alpha$-orbital admissible mapping. The following example shows that there exists a triangular $\alpha$-admissible mapping which is not triangular $\alpha$-admissible.

Example 7 Let $X=\{0,1,2,3\}, d: X \times X \rightarrow R, d(x, y)=|x-y|, T: X \rightarrow X$ such that $T 0=0$, $T 1=2, T 2=1, T 3=3$ and $\alpha: X \times X \rightarrow R, \alpha(x, y)=1$ if $(x, y) \in\{(0,1),(0,2),(1,1),(2,2)$, $(1,2),(2,1),(1,3),(2,3)\}$ and $\alpha(x, y)=0$ otherwise. Since $\alpha(1, T 1)=\alpha(1,2)=1$ and $\alpha(2, T 2)=$ 
$\alpha(2,1)=1, T$ is $\alpha$-orbital admissible. Since $\alpha(0,1)=\alpha(1,2)=\alpha(0,2)=1, \alpha(0,2)=\alpha(2,1)=$ $\alpha(0,1)=1, T$ is triangular $\alpha$-orbital admissible. But $\alpha(0,1)=\alpha(1,3)=1, \alpha(0,3)=0$, so $T$ is not triangular $\alpha$-admissible.

Lemma 8 Let $T: X \rightarrow X$ be a triangular $\alpha$-orbital admissible mapping. Assume that there exists $x_{1} \in X$ such that $\alpha\left(x_{1}, T x_{1}\right) \geq 1$. Define a sequence $\left\{x_{n}\right\}$ by $x_{n+1}=T x_{n}$. Then we have $\alpha\left(x_{n}, x_{m}\right) \geq 1$ for all $m, n \in N$ with $n<m$.

Proof Since $T$ is $\alpha$-orbital admissible and $\alpha\left(x_{1}, T x_{1}\right) \geq 1$, we deduce that $\alpha\left(x_{2}, x_{3}\right)=$ $\alpha\left(T x_{1}, T x_{2}\right) \geq 1$. By continuing this process, we get $\alpha\left(x_{n}, x_{n+1}\right) \geq 1$ for all $n \geq 1$. Suppose that $\alpha\left(x_{n}, x_{m}\right) \geq 1$ and prove that $\alpha\left(x_{n}, x_{m+1}\right) \geq 1$, where $m>n$. Since $T$ is triangular $\alpha$ orbital admissible and $\alpha\left(x_{m}, x_{m+1}\right) \geq 1$, we get that $\alpha\left(x_{n}, x_{m+1}\right) \geq 1$. Hence, we have proved that $\alpha\left(x_{n}, x_{m}\right) \geq 1$ for all $m, n \in N$ with $n<m$.

Theorem 4 Let $(X, d)$ be a complete metric space, $\alpha: X \times X \rightarrow R$ be a function, and let $T: X \rightarrow X$ be a map. Suppose that the following conditions are satisfied:

(1) $T$ is a generalized $\alpha$-Geraghty contraction type mapping;

(2) $T$ is a triangular $\alpha$-orbital admissible mapping;

(3) there exists $x_{1} \in X$ such that $\alpha\left(x_{1}, T x_{1}\right) \geq 1$;

(4) $T$ is continuous.

Then $T$ has a fixed point $x_{*} \in X$ and $\left\{T^{n} x_{1}\right\}$ converges to $x_{*}$.

Proof Let $x_{1} \in X$ such that $\alpha\left(x_{1}, T x_{1}\right) \geq 1$. Define a sequence $\left\{x_{n}\right\}$ by $x_{n+1}=T x_{n}$ for $n \geq 1$. If $x_{n(0)}=x_{n(0)+1}$ for some $n(0) \geq 1$, then obviously $T$ has a fixed point. Hence we suppose that $x_{n} \neq x_{n+1}$ for all $n \geq 1$. By Lemma 8 we have $\alpha\left(x_{n}, x_{n+1}\right) \geq 1$ for all $n \geq 1$. Then we get, for all $n \geq 1$,

$$
d\left(x_{n+1}, x_{n+2}\right)=d\left(T x_{n}, T x_{n+1}\right) \leq \alpha\left(x_{n}, x_{n+1}\right) d\left(T x_{n}, T x_{n+1}\right) \leq \beta\left(M_{T}\left(x_{n}, x_{n+1}\right)\right) M_{T}\left(x_{n}, x_{n+1}\right),
$$

where

$$
\begin{aligned}
M_{T}\left(x_{n}, x_{n+1}\right)= & \max \left\{d\left(x_{n}, x_{n+1}\right), d\left(x_{n}, T x_{n}\right), d\left(x_{n+1}, T x_{n+1}\right),\right. \\
& {\left.\left[d\left(x_{n}, T x_{n+1}\right)+d\left(x_{n+1}, T x_{n}\right)\right] / 2\right\} } \\
= & \max \left\{d\left(x_{n}, x_{n+1}\right), d\left(x_{n+1}, x_{n+2}\right), d\left(x_{n}, x_{n+2}\right) / 2\right\} \\
\leq & \max \left\{d\left(x_{n}, x_{n+1}\right), d\left(x_{n+1}, x_{n+2}\right),\left[d\left(x_{n}, x_{n+1}\right)+d\left(x_{n+1}, x_{n+2}\right)\right] / 2\right\} \\
= & \max \left\{d\left(x_{n}, x_{n+1}\right), d\left(x_{n+1}, x_{n+2}\right)\right\} .
\end{aligned}
$$

Since $\beta\left(M_{T}\left(x_{n}, x_{n+1}\right)\right)<1$, the case $d\left(x_{n}, x_{n+1}\right) \leq d\left(x_{n+1}, x_{n+2}\right)$ is impossible, so we have $d\left(x_{n}, x_{n+1}\right)>d\left(x_{n+1}, x_{n+2}\right)$. Thus, the sequence $\left\{d\left(x_{n}, x_{n+1}\right)\right\}$ is positive and decreasing. Therefore, there exists $r \geq 0$ such that $\lim _{n \rightarrow \infty} d\left(x_{n}, x_{n+1}\right)=r$. We will show that $r=0$. Suppose, to the contrary, that $r>0$. Then we have

$$
d\left(x_{n+1}, x_{n+2}\right) / d\left(x_{n}, x_{n+1}\right) \leq \beta\left(M_{T}\left(x_{n}, x_{n+1}\right)\right)<1 .
$$

This implies that $\lim _{n \rightarrow \infty} \beta\left(M_{T}\left(x_{n}, x_{n+1}\right)\right)=1$. Since $\beta \in \mathcal{F}$, we get $\lim _{n \rightarrow \infty} M_{T}\left(x_{n}, x_{n+1}\right)=$ 0 , and then $\lim _{n \rightarrow \infty} d\left(x_{n}, x_{n+1}\right)=0$. This is a contradiction. 
Next, we shall show that $\left\{x_{n}\right\}$ is a Cauchy sequence. Suppose, to the contrary, that $\left\{x_{n}\right\}$ is not a Cauchy sequence. Then there exists $\epsilon>0$ such that, for all $k \geq 1$, there exists $m(k)>n(k)>k$ with $d\left(x_{n(k)}, x_{m(k)}\right) \geq \epsilon$. Let $m(k)$ be the smallest number satisfying the conditions above. Hence, we have $d\left(x_{n(k)}, x_{m(k)-1}\right)<\epsilon$. Therefore, we get

$$
\epsilon \leq d\left(x_{n(k)}, x_{m(k)}\right) \leq d\left(x_{n(k)}, x_{m(k)-1}\right)+d\left(x_{m(k)-1}, x_{m(k)}\right)<\epsilon+d\left(x_{m(k)-1}, x_{m(k)}\right) .
$$

Letting $k \rightarrow \infty$, we have $\lim _{k \rightarrow \infty} d\left(x_{n(k)}, x_{m(k)}\right)=\epsilon$. Since

$$
\left|d\left(x_{n(k)}, x_{m(k)-1}\right)-d\left(x_{n(k)}, x_{m(k)}\right)\right| \leq d\left(x_{m(k)}, x_{m(k)-1}\right),
$$

we get $\lim _{k \rightarrow \infty} d\left(x_{n(k)}, x_{m(k)-1}\right)=\epsilon$. Similarly, we obtain

$$
\lim _{k \rightarrow \infty} d\left(x_{m(k)}, x_{n(k)-1}\right)=\lim _{k \rightarrow \infty} d\left(x_{m(k)-1}, x_{n(k)-1}\right)=\epsilon .
$$

By Lemma 8 we have $\alpha\left(x_{n(k)-1}, x_{m(k)-1}\right) \geq 1$. Thus, we deduce that

$$
\begin{aligned}
d\left(x_{n(k)}, x_{m(k)}\right) & =d\left(T x_{n(k)-1}, T x_{m(k)-1}\right) \leq \alpha\left(x_{n(k)-1}, x_{m(k)-1}\right) d\left(T x_{n(k)-1}, T x_{m(k)-1}\right) \\
& \leq \beta\left(M_{T}\left(x_{n(k)-1}, x_{m(k)-1}\right)\right) M_{T}\left(x_{n(k)-1}, x_{m(k)-1}\right)
\end{aligned}
$$

where

$$
\begin{aligned}
M_{T}\left(x_{n(k)-1}, x_{m(k)-1}\right)= & \max \left\{d\left(x_{n(k)-1}, x_{m(k)-1}\right), d\left(x_{n(k)-1}, T x_{n(k)-1}\right), d\left(x_{m(k)-1}, T x_{m(k)-1}\right),\right. \\
& {\left.\left[d\left(x_{n(k)-1}, T x_{m(k)-1}\right)+d\left(x_{m(k)-1}, T x_{n(k)-1}\right)\right] / 2\right\} } \\
= & \max \left\{d\left(x_{n(k)-1}, x_{m(k)-1}\right), d\left(x_{n(k)-1}, x_{n(k)}\right), d\left(x_{m(k)-1}, x_{m(k)}\right),\right. \\
& {\left.\left[d\left(x_{n(k)-1}, x_{m(k)}\right)+d\left(x_{m(k)-1}, x_{n(k)}\right)\right] / 2\right\} . }
\end{aligned}
$$

Clearly, we deduce that

$$
\lim _{k \rightarrow \infty} M_{T}\left(x_{n(k)-1}, x_{m(k)-1}\right)=\epsilon .
$$

Hence, we have

$$
d\left(x_{n(k)}, x_{m(k)}\right) / M_{T}\left(x_{n(k)-1}, x_{m(k)-1}\right) \leq \beta\left(M_{T}\left(x_{n(k)-1}, x_{m(k)-1}\right)\right) .
$$

Letting $k \rightarrow \infty$, we conclude that $\lim _{k \rightarrow \infty} \beta\left(M_{T}\left(x_{n(k)-1}, x_{m(k)-1}\right)\right)=1$, which yields that $\lim _{k \rightarrow \infty} M_{T}\left(x_{n(k)-1}, x_{m(k)-1}\right)=0$. Hence, $\epsilon=0$, which is a contradiction. Thus, we get that $\left\{x_{n}\right\}$ is a Cauchy sequence. Since $X$ is a complete metric space, it follows that there exists $x_{*}=\lim _{n \rightarrow \infty} x_{n} \in X$. By the continuity of $T$, we get $\lim _{n \rightarrow \infty} T x_{n}=T x_{*}$, and so $x_{*}=T x_{*}$, which means that $x_{*}$ is a fixed point of $T$.

Like in [13] we can replace the continuity of the operator $T$ by a suitable condition.

Theorem 5 Let $(X, d)$ be a complete metric space, $\alpha: X \times X \rightarrow R$ be a function, and let $T: X \rightarrow X$ be a map. Suppose that the following conditions are satisfied: 
(1) $T$ is a generalized $\alpha$-Geraghty contraction type mapping;

(2) $T$ is triangular $\alpha$-orbital admissible mapping;

(3) there exists $x_{1} \in X$ such that $\alpha\left(x_{1}, T x_{1}\right) \geq 1$;

(4) if $\left\{x_{n}\right\}$ is a sequence in $X$ such that $\alpha\left(x_{n}, x_{n+1}\right) \geq 1$ for all $n$ and $x_{n} \rightarrow x \in X$ as $n \rightarrow \infty$, then there exists a subsequence $\left\{x_{n(k)}\right\}$ of $\left\{x_{n}\right\}$ such that $\alpha\left(x_{n(k)}, x\right) \geq 1$ for all $k$.

Then $T$ has a fixed point $x_{*} \in X$ and $\left\{T^{n} x_{1}\right\}$ converges to $x_{*}$.

Proof Following the lines in the proof of Theorem 4, we have that the sequence $\left\{x_{n}\right\}$ defined by $x_{n+1}=T x_{n}$ for all $n \geq 1$ converges to $x_{*} \in X$. By condition (4) of the hypothesis, we deduce that there exists a subsequence $\left\{x_{n(k)}\right\}$ of $\left\{x_{n}\right\}$ such that $\alpha\left(x_{n(k)}, x_{*}\right) \geq 1$ for all $k$. Therefore, we have

$$
\begin{aligned}
d\left(x_{n(k)+1}, T x_{*}\right) & =d\left(T x_{n(k)}, T x_{*}\right) \leq \alpha\left(x_{n(k)}, x_{*}\right) d\left(T x_{n(k)}, T x_{*}\right) \\
& \leq \beta\left(M_{T}\left(x_{n(k)}, x_{*}\right)\right) M_{T}\left(x_{n(k)}, x_{*}\right),
\end{aligned}
$$

where

$$
\begin{aligned}
M_{T}\left(x_{n(k)}, x_{*}\right)= & \max \left\{d\left(x_{n(k)}, x_{*}\right), d\left(x_{n(k)}, T x_{n(k)}\right), d\left(x_{*}, T x_{*}\right),\right. \\
& {\left.\left[d\left(x_{n(k)}, T x_{*}\right)+d\left(x_{*}, T x_{n(k)}\right)\right] / 2\right\} } \\
= & \max \left\{d\left(x_{n(k)}, x_{*}\right), d\left(x_{n(k)}, x_{n(k)+1}\right), d\left(x_{*}, T x_{*}\right),\right. \\
& {\left.\left[d\left(x_{n(k)}, T x_{*}\right)+d\left(x_{*}, x_{n(k)+1}\right)\right] / 2\right\} . }
\end{aligned}
$$

Now, we suppose that $T x_{*} \neq x_{*}$, that is, $d\left(x_{*}, T x_{*}\right)>0$. Letting $k \rightarrow \infty$ in the above equality, we get that

$$
\lim _{k \rightarrow \infty} M_{T}\left(x_{n(k)}, x_{*}\right)=d\left(x_{*}, T x_{*}\right)
$$

Since $d\left(x_{n(k)+1}, T x_{*}\right) / M_{T}\left(x_{n(k)}, x_{*}\right) \leq \beta\left(M_{T}\left(x_{n(k)}, x_{*}\right)\right)$ for all $k$, letting $k \rightarrow \infty$, we conclude that $\lim _{k \rightarrow \infty} \beta\left(M_{T}\left(x_{n(k)}, x_{*}\right)\right)=1$. This implies $\lim _{k \rightarrow \infty} M_{T}\left(x_{n(k)}, x_{*}\right)=0$. Hence, $d\left(x_{*}, T x_{*}\right)=0$. This is a contradiction. Therefore, $T x_{*}=x_{*}$.

For the uniqueness of a fixed point of a generalized $\alpha$-Geraghty contraction type mapping, we consider the following hypothesis:

(K) For all $x \neq y \in X$, there exists $v \in X$ such that $\alpha(x, v) \geq 1, \alpha(y, v) \geq 1$ and $\alpha(v, T v) \geq 1$.

Remark 9 Replacing condition (3) with condition (K) in the hypotheses of Theorem 4 or Theorem 5, we obtain that $x_{*}$ is the unique fixed point of $T$. Suppose that $x_{*}$ and $y_{*}$ are two fixed points of $T$ such that $x_{*} \neq y_{*}$. Then, by (K), there exists $v \in X$ such that $\alpha\left(x_{*}, v\right) \geq 1$, $\alpha\left(y_{*}, v\right) \geq 1$ and $\alpha(v, T v) \geq 1$. Since $T$ is a triangular $\alpha$-orbital admissible mapping, we get that $\alpha\left(x_{*}, T^{n} v\right) \geq 1$ and $\alpha\left(y_{*}, T^{n} v\right) \geq 1$ for all $n \geq 1$. Thus we have

$$
d\left(x_{*}, T^{n+1} v\right) \leq \alpha\left(x_{*}, T^{n} v\right) d\left(T x_{*}, T^{n+1} v\right) \leq \beta\left(M_{T}\left(x_{*}, T^{n} v\right)\right) M_{T}\left(x_{*}, T^{n} v\right)
$$


for all $n \geq 1$, where

$$
\begin{aligned}
M_{T}\left(x_{*}, T^{n} v\right)= & \max \left\{d\left(x_{*}, T^{n} v\right), d\left(x_{*}, T x_{*}\right), d\left(T^{n} v, T^{n+1} v\right),\right. \\
& {\left.\left[d\left(x_{*}, T^{n+1} v\right)+d\left(T x_{*}, T^{n} v\right)\right] / 2\right\} } \\
= & \max \left\{d\left(x_{*}, T^{n} v\right), d\left(T^{n} v, T^{n+1} v\right),\left[d\left(x_{*}, T^{n+1} v\right)+d\left(x_{*}, T^{n} v\right)\right] / 2\right\} .
\end{aligned}
$$

By Theorem 4 (resp. Theorem 5) we deduce that the sequence $\left\{T^{n} v\right\}$ converges to a fixed point $z_{*}$ of $T$. Letting $n \rightarrow \infty$ in the above equality, we get $\lim _{n \rightarrow \infty} M_{T}\left(x_{*}, T^{n} v\right)=d\left(x_{*}, z_{*}\right)$. If we suppose $x_{*} \neq z_{*}$, then we have $d\left(x_{*}, T^{n+1} v\right) / M_{T}\left(x_{*}, T^{n} v\right) \leq \beta\left(M_{T}\left(x_{*}, T^{n} v\right)\right)$, and letting $n \rightarrow \infty$, we deduce that $\lim _{n \rightarrow \infty} \beta\left(M_{T}\left(x_{*}, T^{n} v\right)\right)=1$. This implies $\lim _{n \rightarrow \infty} M_{T}\left(x_{*}, T^{n} v\right)=0$, so $d\left(x_{*}, z_{*}\right)=0$, which is a contradiction. Therefore, $x_{*}=z_{*}$. Similarly, we get $y_{*}=z_{*}$. Hence, $x_{*}=y_{*}$, which is a contradiction.

Example 10 Let $X=[-2,-1] \cup\{0\} \cup[1,2], d: X \times X \rightarrow R, d(x, y)=|x-y|, T: X \rightarrow X$ such that $T x=-x$ if $x \in[-2,-1) \cup(1,2], T x=0$ if $x \in\{-1,0,1\}$, and $\alpha: X \times X \rightarrow R$, $\alpha(x, y)=1$ if $x y \geq 0$ and $\alpha(x, y)=0$ otherwise. Then $T$ satisfies the conditions of Theorem 5. Clearly, $X$ is a complete metric space. If $\alpha(x, T x) \geq 1$, then $x T x \geq 0$, so $T x=0$, which implies $\alpha\left(T x, T^{2} x\right) \geq 1$. Hence $T$ is an $\alpha$-orbital admissible mapping. For $\alpha(x, y) \geq 1$ and $\alpha(y, T y) \geq 1$, we have $T y=0$. Thus, $x T y=0$ and $\alpha(x, T y) \geq 1$. Therefore, $T$ is a triangular $\alpha$-orbital admissible mapping. Also, $\alpha(1, T 1) \geq 1$ and if $\left\{x_{n}\right\}$ is a sequence in $X$ such that $\alpha\left(x_{n}, x_{n+1}\right) \geq 1$ for all $n$ and $x_{n} \rightarrow x \in X$ as $n \rightarrow \infty$, then $x=0$ and $\alpha\left(x_{n}, x\right) \geq 1$ for all $n$. For $x, y \in[-2,-1)$, we have $d(T x, T y)=|x-y| \leq 1$ and $M_{T}(x, y) \geq-2 x \geq 2$. Thus $d(T x, T y) \leq$ $M_{T}(x, y) / 2$. The case $x, y \in(1,2]$ is similar. If $x \in[-2,-1) \cup(1,2]$ and $y \in\{-1,0,1\}$, then $d(T x, T y)=|x|, M_{T}(x, y) \geq 2|x|$, so $d(T x, T y) \leq M_{T}(x, y) / 2$. For $x, y \in\{-1,0,1\}$, we have $d(T x, T y)=0 \leq M_{T}(x, y) / 2$. Therefore, taking $\beta:[0, \infty) \rightarrow[0,1), \beta(t)=1 / 2$, we obtain that $T$ is a generalized $\alpha$-Geraghty contraction type mapping. Hence, $T$ satisfies all the conditions of Theorem 5. However, since $\alpha(-2,0)=\alpha(0,2)=1, \alpha(-2,2)=0, T$ is not a triangular $\alpha$-admissible mapping.

\section{$3 \alpha$-Orbital attractive mappings}

Now we introduce a new concept.

Definition 11 Let $T: X \rightarrow X$ be a map and $\alpha: X \times X \rightarrow R$ be a function. Then $T$ is said to be $\alpha$-orbital attractive if

$$
\alpha(x, T x) \geq 1 \quad \text { implies } \quad \alpha(x, y) \geq 1 \text { or } \alpha(y, T x) \geq 1
$$

for every $y \in X$.

Theorem 6 Let $(X, d)$ be a complete metric space, $\alpha: X \times X \rightarrow R$ be a function, and let $T: X \rightarrow X$ be a map. Suppose that the following conditions are satisfied:

(1) $T$ is a generalized $\alpha$-Geraghty contraction type mapping;

(2) $T$ is $\alpha$-orbital admissible;

(3) there exists $x_{1} \in X$ such that $\alpha\left(x_{1}, T x_{1}\right) \geq 1$;

(4) $T$ is $\alpha$-orbital attractive.

Then $T$ has a unique fixed point $x_{*} \in X$ and $\left\{T^{n} x_{1}\right\}$ converges to $x_{*}$. 
Proof Let $x_{1} \in X$ such that $\alpha\left(x_{1}, T x_{1}\right) \geq 1$. Define a sequence $\left\{x_{n}\right\}$ by $x_{n+1}=T x_{n}$ for $n \geq 1$. If $x_{n(0)}=x_{n(0)+1}$ for some $n(0) \geq 1$, then obviously $T$ has a fixed point. Hence we suppose that $x_{n} \neq x_{n+1}$ for all $n \geq 1$. Since $T$ is $\alpha$-orbital admissible, we have

$$
\alpha\left(x_{1}, x_{2}\right)=\alpha\left(x_{1}, T x_{1}\right) \geq 1 \quad \text { implies } \quad \alpha\left(T x_{1}, T x_{2}\right)=\alpha\left(x_{2}, x_{3}\right) \geq 1
$$

Inductively, we get $\alpha\left(x_{n}, x_{n+1}\right) \geq 1$ for all $n \geq 1$. Then we obtain

$$
d\left(x_{n}, x_{n+1}\right)=d\left(T x_{n}, T x_{n+1}\right) \leq \alpha\left(x_{n}, x_{n+1}\right) d\left(T x_{n}, T x_{n+1}\right) \leq \beta\left(M_{T}\left(x_{n}, x_{n+1}\right)\right) M_{T}\left(x_{n}, x_{n+1}\right)
$$

for all $n \geq 1$, where

$$
\begin{aligned}
M_{T}\left(x_{n}, x_{n+1}\right)= & \max \left\{d\left(x_{n}, x_{n+1}\right), d\left(x_{n}, T x_{n}\right), d\left(x_{n+1}, T x_{n+1}\right),\right. \\
& {\left.\left[d\left(x_{n}, T x_{n+1}\right)+d\left(x_{n+1}, T x_{n}\right)\right] / 2\right\} } \\
= & \max \left\{d\left(x_{n}, x_{n+1}\right), d\left(x_{n+1}, x_{n+2}\right), d\left(x_{n}, x_{n+2}\right) / 2\right\} \\
\leq & \max \left\{d\left(x_{n}, x_{n+1}\right), d\left(x_{n+1}, x_{n+2}\right),\left[d\left(x_{n}, x_{n+1}\right)+d\left(x_{n+1}, x_{n+2}\right)\right] / 2\right\} \\
= & \max \left\{d\left(x_{n}, x_{n+1}\right), d\left(x_{n+1}, x_{n+2}\right)\right\} .
\end{aligned}
$$

If $d\left(x_{n}, x_{n+1}\right) \leq d\left(x_{n+1}, x_{n+2}\right)$, we have

$$
d\left(x_{n+1}, x_{n+2}\right) \leq \beta\left(d\left(x_{n+1}, x_{n+2}\right)\right) d\left(x_{n+1}, x_{n+2}\right)<d\left(x_{n+1}, x_{n+2}\right),
$$

which is a contradiction. Thus, we get

$$
d\left(x_{n+1}, x_{n+2}\right) \leq \beta\left(d\left(x_{n}, x_{n+1}\right)\right) d\left(x_{n}, x_{n+1}\right)<d\left(x_{n}, x_{n+1}\right) .
$$

Therefore, the sequence $\left\{d\left(x_{n}, x_{n+1}\right)\right\}$ is positive and nonincreasing. Hence, there exists $r \geq 0$ such that $\lim _{n \rightarrow \infty} d\left(x_{n}, x_{n+1}\right)=r$. We will show that $r=0$. Suppose, on the contrary, that $r>0$. Then we have

$$
d\left(x_{n+1}, x_{n+2}\right) / d\left(x_{n}, x_{n+1}\right) \leq \beta\left(d\left(x_{n}, x_{n+1}\right)\right)<1 .
$$

This implies that $\lim _{n \rightarrow \infty} \beta\left(x_{n}, x_{n+1}\right)=1$. Since $\beta \in \mathcal{F}$, we obtain that $\lim _{n \rightarrow \infty} d\left(x_{n}, x_{n+1}\right)=$ 0 , which is a contradiction. Hence $r=0$.

Now, we shall show that $\left\{x_{n}\right\}$ is a Cauchy sequence. Suppose, on the contrary, that $\left\{x_{n}\right\}$ is not a Cauchy sequence. Then there exists $\epsilon>0$ such that, for all $k \geq 1$, there exists $m(k)>n(k)>k$ with $d\left(x_{n(k)}, x_{m(k)}\right) \geq \epsilon$. Let $m(k)$ be the smallest number satisfying the conditions above. Hence, we have $d\left(x_{n(k)}, x_{m(k)-1}\right)<\epsilon$. Therefore, we get

$$
\epsilon \leq d\left(x_{n(k)}, x_{m(k)}\right) \leq d\left(x_{n(k)}, x_{m(k)-1}\right)+d\left(x_{m(k)-1}, x_{m(k)}\right)<\epsilon+d\left(x_{m(k)-1}, x_{m(k)}\right) .
$$

Letting $k \rightarrow \infty$, we have $\lim _{k \rightarrow \infty} d\left(x_{n(k)}, x_{m(k)}\right)=\epsilon$. Since

$$
\left|d\left(x_{n(k)}, x_{m(k)-1}\right)-d\left(x_{n(k)}, x_{m(k)}\right)\right| \leq d\left(x_{m(k)}, x_{m(k)-1}\right),
$$


we get $\lim _{k \rightarrow \infty} d\left(x_{n(k)}, x_{m(k)-1}\right)=\epsilon$. Similarly, we obtain

$$
\lim _{k \rightarrow \infty} d\left(x_{m(k)}, x_{n(k)-1}\right)=\lim _{k \rightarrow \infty} d\left(x_{m(k)-1}, x_{n(k)-1}\right)=\lim _{k \rightarrow \infty} d\left(x_{m(k)-1}, x_{n(k)+1}\right)=\epsilon .
$$

Since $\alpha\left(x_{n(k)-1}, x_{n(k)}\right) \geq 1$ and $T$ is $\alpha$-orbital attractive, we have

$$
\alpha\left(x_{n(k)-1}, x_{m(k)-1}\right) \geq 1 \quad \text { or } \quad \alpha\left(x_{m(k)-1}, x_{n(k)}\right) \geq 1 .
$$

Hence, we get two cases as follows.

(1) There exists an infinite subset $I$ of $N$ such that $\alpha\left(x_{n(k)-1}, x_{m(k)-1}\right) \geq 1$ for every $k \in I$.

(2) There exists an infinite subset $J$ of $N$ such that $\alpha\left(x_{m(k)-1}, x_{n(k)}\right) \geq 1$ for every $k \in J$.

In the first case, we have

$$
\begin{aligned}
d\left(x_{n(k)}, x_{m(k)}\right) & =d\left(T x_{n(k)-1}, T x_{m(k)-1}\right) \leq \alpha\left(x_{n(k)-1}, x_{m(k)-1}\right) d\left(T x_{n(k)-1}, T x_{m(k)-1}\right) \\
& \leq \beta\left(M_{T}\left(x_{n(k)-1}, x_{m(k)-1}\right)\right) M_{T}\left(x_{n(k)-1}, x_{m(k)-1}\right)
\end{aligned}
$$

where

$$
\begin{aligned}
M_{T}\left(x_{n(k)-1}, x_{m(k)-1}\right)= & \max \left\{d\left(x_{n(k)-1}, x_{m(k)-1}\right), d\left(x_{n(k)-1}, T x_{n(k)-1}\right), d\left(x_{m(k)-1}, T x_{m(k)-1}\right),\right. \\
& {\left.\left[d\left(x_{n(k)-1}, T x_{m(k)-1}\right)+d\left(x_{m(k)-1}, T x_{n(k)-1}\right)\right] / 2\right\} } \\
= & \max \left\{d\left(x_{n(k)-1}, x_{m(k)-1}\right), d\left(x_{n(k)-1}, x_{n(k)}\right), d\left(x_{m(k)-1}, x_{m(k)}\right),\right. \\
& {\left.\left[d\left(x_{n(k)-1}, x_{m(k)}\right)+d\left(x_{m(k)-1}, x_{n(k)}\right)\right] / 2\right\} . }
\end{aligned}
$$

Letting $k \rightarrow \infty, k \in I$, we conclude that

$$
\lim _{k \rightarrow \infty, k \in I} M_{T}\left(x_{n(k)-1}, x_{m(k)-1}\right)=\epsilon,
$$

and since

$$
d\left(x_{n(k)}, x_{m(k)}\right) / M_{T}\left(x_{n(k)-1}, x_{m(k)-1}\right) \leq \beta\left(M_{T}\left(x_{n(k)-1}, x_{m(k)-1}\right)\right),
$$

we get that

$$
\lim _{k \rightarrow \infty, k \in I} \beta\left(M_{T}\left(x_{n(k)-1}, x_{m(k)-1}\right)\right)=1 .
$$

Since $\beta \in \mathcal{F}$, we obtain that

$$
\lim _{k \rightarrow \infty, \in I} M_{T}\left(x_{n(k)-1}, x_{m(k)-1}\right)=0,
$$

which is a contradiction.

In the second case, we have

$$
\begin{aligned}
d\left(x_{m(k)}, x_{n(k)+1}\right) & =d\left(T x_{m(k)-1}, T x_{n(k)}\right) \leq \alpha\left(x_{m(k)-1}, x_{n(k)}\right) d\left(T x_{m(k)-1}, T x_{n(k)}\right) \\
& \leq \beta\left(M_{T}\left(x_{m(k)-1}, x_{n(k)}\right)\right) M_{T}\left(x_{m(k)-1}, x_{n(k)}\right),
\end{aligned}
$$


where

$$
\begin{aligned}
M_{T}\left(x_{m(k)-1}, x_{n(k)}\right)= & \max \left\{d\left(x_{m(k)-1}, x_{n(k)}\right), d\left(x_{m(k)-1}, T x_{m(k)-1}\right), d\left(x_{n(k)}, T x_{n(k)}\right),\right. \\
& {\left.\left[d\left(x_{m(k)-1}, T x_{n(k)}\right)+d\left(x_{n(k)}, T x_{m(k)-1}\right)\right] / 2\right\} } \\
= & \max \left\{d\left(x_{m(k)-1}, x_{n(k)}\right), d\left(x_{m(k)-1}, x_{m(k)}\right), d\left(x_{n(k)}, x_{n(k)+1}\right),\right. \\
& {\left.\left[d\left(x_{m(k)-1}, x_{n(k)+1}\right)+d\left(x_{m(k)}, x_{n(k)}\right)\right] / 2\right\} . }
\end{aligned}
$$

Letting $k \rightarrow \infty, k \in J$, we conclude that

$$
\lim _{k \rightarrow \infty, k \in J} M_{T}\left(x_{m(k)-1}, x_{n(k)}\right)=\epsilon,
$$

and since

$$
d\left(x_{m(k)}, x_{n(k)+1}\right) / M_{T}\left(x_{m(k)-1}, x_{n(k)}\right) \leq \beta\left(M_{T}\left(x_{m(k)-1}, x_{n(k)}\right)\right),
$$

we get that

$$
\lim _{k \rightarrow \infty, k \in J} \beta\left(M_{T}\left(x_{m(k)-1}, x_{n(k)}\right)\right)=1 .
$$

Since $\beta \in \mathcal{F}$, we obtain that

$$
\lim _{k \rightarrow \infty, k \in J} M_{T}\left(x_{m(k)-1}, x_{n(k)}\right)=0,
$$

which is a contradiction. Thus, we get that $\left\{x_{n}\right\}$ is a Cauchy sequence. Since $X$ is a complete metric space, it follows that there exists $x_{*}=\lim _{n \rightarrow \infty} x_{n} \in X$.

We claim that $x_{*}=T x_{*}$. Suppose, on the contrary, that $x_{*} \neq T x_{*}$. Since $T$ is $\alpha$-orbital attractive, we have for every $n \geq 1$ that $\alpha\left(x_{n}, x_{*}\right) \geq 1$ or $\alpha\left(x_{*}, x_{n+1}\right) \geq 1$. Hence, there exists a subsequence $\left\{x_{n(k)}\right\}$ of $\left\{x_{n}\right\}$ such that $\alpha\left(x_{n(k)}, x_{*}\right) \geq 1$ or $\alpha\left(x_{*}, x_{n(k)}\right) \geq 1$ for all $k \geq 1$. In the first case, we have

$$
d\left(x_{n(k)+1}, T x *\right) \leq \alpha\left(x_{n(k)}, x_{*}\right) d\left(x_{n(k)+1}, T x_{*}\right) \leq \beta\left(M_{T}\left(x_{n(k)}, x_{*}\right)\right) M_{T}\left(x_{n(k)}, x_{*}\right),
$$

for all $k \geq 1$, where

$$
\begin{aligned}
M_{T}\left(x_{n(k)}, x_{*}\right)= & \max \left\{d\left(x_{n(k)}, x_{*}\right), d\left(x_{n(k)}, T x_{n(k)}\right), d\left(x_{*}, T x_{*}\right),\right. \\
& {\left.\left[d\left(x_{n(k)}, T x_{*}\right)+d\left(T x_{n(k)}, x_{*}\right)\right] / 2\right\} . }
\end{aligned}
$$

Letting $k \rightarrow \infty$, we conclude that

$$
\lim _{k \rightarrow \infty} M_{T}\left(x_{n(k)}, x_{*}\right)=d\left(x_{*}, T x_{*}\right)
$$

and since

$$
d\left(x_{n(k)+1}, T x *\right) / M_{T}\left(x_{n(k)}, x_{*}\right) \leq \beta\left(M_{T}\left(x_{n(k)}, x_{*}\right)\right),
$$


we have

$$
\lim _{k \rightarrow \infty} \beta\left(M_{T}\left(x_{n(k)}, x_{*}\right)\right)=1 .
$$

Since $\beta \in \mathcal{F}$, we obtain that

$$
\lim _{k \rightarrow \infty} M_{T}\left(x_{m(k)-1}, x_{n(k)}\right)=0,
$$

which is a contradiction. The second case is similar. Therefore, $x_{*}=T x_{*}$.

If $y_{*}$ is another fixed point of $T$, from the hypothesis we deduce that $\alpha\left(x_{n}, y_{*}\right) \geq 1$ or $\alpha\left(y_{*}, x_{n+1}\right) \geq 1$. Hence, there exists a subsequence $\left\{x_{n(k)}\right\}$ of $\left\{x_{n}\right\}$ such that $\alpha\left(x_{n(k)}, y_{*}\right) \geq 1$ or $\alpha\left(y_{*}, x_{n(k)}\right) \geq 1$ for all $k \geq 1$. In the first case, we have

$$
d\left(x_{n(k)+1}, T y *\right) \leq \alpha\left(x_{n(k)}, y_{*}\right) d\left(x_{n(k)+1}, T y_{*}\right) \leq \beta\left(M_{T}\left(x_{n(k)}, y_{*}\right)\right) M_{T}\left(x_{n(k)}, y_{*}\right),
$$

for all $k \geq 1$, where

$$
\begin{aligned}
M_{T}\left(x_{n(k)}, y_{*}\right)= & \max \left\{d\left(x_{n(k)}, y_{*}\right), d\left(x_{n(k)}, T x_{n(k)}\right), d\left(y_{*}, T y_{*}\right),\right. \\
& {\left.\left[d\left(x_{n(k)}, T y_{*}\right)+d\left(T x_{n(k)}, y_{*}\right)\right] / 2\right\} . }
\end{aligned}
$$

Letting $k \rightarrow \infty$, we conclude that

$$
\lim _{k \rightarrow \infty} M_{T}\left(x_{n(k)}, y_{*}\right)=d\left(x_{*}, y_{*}\right)
$$

and since

$$
d\left(x_{n(k)+1}, T y *\right) / M_{T}\left(x_{n(k)}, y_{*}\right) \leq \beta\left(M_{T}\left(x_{n(k)}, y_{*}\right)\right),
$$

we obtain

$$
\lim _{k \rightarrow \infty} \beta\left(M_{T}\left(x_{n(k)}, y_{*}\right)\right)=1
$$

Since $\beta \in \mathcal{F}$, we get that

$$
\lim _{k \rightarrow \infty} M_{T}\left(x_{n(k)}, y_{*}\right)=0,
$$

so $d\left(x_{*}, y_{*}\right)=0$. This is a contradiction. The second case is similar.

Example 12 Let $X=\{0,8,9,10\}, d: X \times X \rightarrow R, d(x, y)=|x-y|, T: X \rightarrow X$ such that $T 0=T 8=9, T 9=T 10=10, \alpha: X \times X \rightarrow R, \alpha(x, y)=0$ if $(x, y) \in\{(8,9),(9,8)\}$ and $\alpha(x, y)=$ 1 otherwise. Obviously, $T$ is $\alpha$-orbital admissible and $\alpha$-orbital attractive. Also, $T$ is a generalized $\alpha$-Geraghty contraction type mapping if we take $\beta:[0, \infty) \rightarrow[0,1), \beta(t)=1 / 2$. Hence $T$ satisfies all the conditions of Theorem 6 . However, since $\alpha(8,0)=\alpha(0, T 0)=1$, $\alpha(8, T 0)=0, T$ is not triangular $\alpha$-orbital admissible. Note that $d(T 8, T 9)=M_{T}(8,9)=1$. 


\section{Competing interests}

The author declares that they have no competing interests.

\section{Received: 29 April 2014 Accepted: 11 August 2014 Published: 03 Sep 2014}

\section{References}

1. Banach, S: Sur les opérationes dans les ensembles abstraits et leur application aux équation intégrales. Fundam. Math. 3, 133-181 (1922)

2. Rhoades, BE: A comparison of various definitions of contractive mappings. Trans. Am. Math. Soc. 226, 257-290 (1977)

3. Amini-Harandi, A, Emami, H: A fixed point theorem for contraction type maps in partially ordered metric spaces and applications to ordinary differential equations. Nonlinear Anal. 72, 2238-2242 (2010)

4. Agarwal, RP, El-Gebeily, MA, O'Regan, D: Generalized contractions in partially ordered metric spaces. Appl. Anal. 87, 1-8 (2008)

5. Cho, SH, Bae, JS: Common fixed point theorems for mappings satisfying property (E,A) on cone metric spaces. Math. Comput. Model. 53, 945-951 (2011)

6. Geraghty, M: On contractive mappings. Proc. Am. Math. Soc. 40, 604-608 (1973)

7. Hille, E, Phillips, RS: Functional Analysis and Semi-Groups. Amer. Math. Soc. Colloq. Publ., vol. 31. Am. Math. Soc, Providence (1957)

8. Huang, LG, Zhang, X: Cone metric space and fixed point theorems of contractive mappings. J. Math. Anal. Appl. $332(2), 1468-1476(2007)$

9. Khamsi, MA, Kreinovich, VY: Fixed point theorems for dissipative mappings in complete probabilistic metric spaces. Math. Jpn. 44, 513-520 (1996)

10. Yang, SK, Bae, JS, Cho, SH: Coincidence and common fixed and periodic point theorems in cone metric spaces. Comput. Math. Appl. 61, 170-177 (2011)

11. Caballero, J, Harjani, J, Sadarangani, K: A best proximity point theorem for Geraghty-contractions. Fixed Point Theory Appl. 2012, Article ID 231 (2012)

12. Gordji, ME, Ramezami, M, Cho, YJ, Pirbavafa, S: A generalization of Geraghty's theorem in partially ordered metric spaces and applications to ordinary differential equations. Fixed Point Theory Appl. 2012, Article ID 74 (2012)

13. Cho, SH, Bae, JS, Karapınar, E: Fixed point theorems for $\alpha$-Geraghty contraction type maps in metric spaces. Fixed Point Theory Appl. 2013, Article ID 329 (2013)

14. Karapınar, E, Samet, B: Generalized $\alpha$ - $\psi$-contractive type mappings and related fixed point theorems with applications. Abstr. Appl. Anal. 2012, Article ID 793486 (2012)

15. Karapınar, E: On best proximity point of $\psi$-Geraghty contractions. Fixed Point Theory Appl. (2013). doi:10.1186/1687-1812-2013-200

16. Karapınar, E, Kumam, P, Salimi, P: On $\alpha$ - $\psi$-Meir-Keeler contractive mappings. Fixed Point Theory Appl. 2013, Article ID 94 (2013)

17. Karapınar, E: Edelstein type fixed point theorems. Fixed Point Theory Appl. 2012, Article ID 107 (2012)

18. Karapınar, E, Samet, B: A note on $\alpha$-Geraghty type contractions. Fixed Point Theory Appl. (2014). doi:10.1186/1687-1812-2014-26

19. Karapınar, E: $\alpha-\psi$-Geraghty contraction type mappings and some related fixed point results. Filomat 28, $37-48$ (2014)

20. Aydi, H, Karapınar, E, Erhan, I, Salimi, P: Best proximity points of generalized almost $\psi$-Geraghty contractive non-self-mappings. Fixed Point Theory Appl. 2014, Article ID 32 (2014)

21. Bilgili, N, Karapınar, E, Sadarangani, K: A generalization for the best proximity point of Geraghty-contractions. J. Inequal. Appl. 2013, Article ID 286 (2013)

22. Mongkolkeha, C, Cho, YE, Kumam, P: Best proximity points for Geraghty's proximal contraction mappings. Fixed Point Theory Appl. 2013, Article ID 180 (2013)

23. Chaipunya, P, Cho, YE, Kumam, P: Geraghty-type theorems in modular metric spaces with an application to partial differential equation. Adv. Differ. Equ. 2012, Article ID 83 (2012)

24. Samet, B, Vetro, C, Vetro, P: Fixed point theorems for $\alpha$ - $\psi$-contractive mappings. Nonlinear Anal. 75, 2154-2165 (2012)

10.1186/1687-1812-2014-190

Cite this article as: Popescu: Some new fixed point theorems for $\alpha$-Geraghty contraction type maps in metric spaces. Fixed Point Theory and Applications 2014, 2014:190 